\title{
Melatonin inhibits cell proliferation in a rat model of breast hyperplasia by mediating the PTEN/AKT pathway
}

\author{
XIANGJIAN ZHANG ${ }^{1}$, YINGQUN NIU ${ }^{2}$ and YIBO HUANG ${ }^{2}$ \\ ${ }^{1}$ Department of Surgical Oncology, Wenzhou Central Hospital, Wenzhou, Zhejiang 325000; ${ }^{2}$ Department of Surgical Oncology, \\ The Second Affiliated Hospital of Zhejiang Chinese Medical University, Hangzhou, Zhejiang 310005, P.R. China
}

Received September 8, 2020; Accepted February 19, 2021

DOI: $10.3892 /$ or.2021.8017

\begin{abstract}
In the present study, a rat model of breast hyperplasia was established via the administration of estradiol benzoate and progesterone. Subsequent changes associated with breast hyperplasia were then investigated by measuring the diameter and height of the nipples and by staining breast tissue with hematoxylin and eosin. The proliferation and apoptosis of hyperplastic cells in the breast tissue were then determined by analyzing the expression of proliferating cell nuclear antigen (PCNA) and cleaved-caspase-3 by immunohistochemistry and TUNEL staining. We also determined the expression of proteins associated with the phosphatase and tensin homolog (PTEN)/protein kinase B (AKT) signaling pathway by western blotting. Melatonin treatment led to a significant reduction in the degree of breast hyperplasia $(\mathrm{P}<0.05)$, a significant reduction in PCNA, a significant increase in the level of apoptosis $(\mathrm{P}<0.05)$, a significant increase in PTEN $(\mathrm{P}<0.05)$, and a significant reduction in AKT/p-AKT $(\mathrm{P}<0.05)$. Furthermore, melatonin significantly decreased the aggravation of breast hyperplasia induced by application of a PTEN inhibitor. Melatonin reduced the degree of breast hyperplasia, reduced the proliferation of hyperplastic breast tissue cells, and promoted cell apoptosis in hyperplastic tissue. These effects were achieved by the specific regulation of proteins in the PTEN/PI3K/AKT axis.
\end{abstract}

Correspondence to: Dr Yibo Huang, Department of Surgical Oncology, The Second Affiliated Hospital of Zhejiang Chinese Medical University, 318 Chaowang Road, Hangzhou, Zhejiang 310005, P.R. China

E-mail: huangyibomr@163.com

Abbreviations: ER, estrogen receptor; PR, progesterone receptor; PTEN, phosphatase and tensin homolog; AKT, protein kinase B/serine/ threonine protein kinase; PCNA, proliferating cell nuclear antigen; PI3K, class I phosphatidylinositol-3-kinase; PIP3, phosphatidylinositol3-triphosphate; PIP2, phosphatidylinositol-4-diphosphate

Key words: breast hyperplasia, melatonin, PTEN/AKT pathway, mammary gland hyperplasia, hyperplastic disease of the breast

\section{Introduction}

Breast hyperplasia is a common disease that generally occurs in women and accounts for more than $90 \%$ of all breast diseases. Breast hyperplasia is characterized by proliferative pathological changes in the breast acini, epithelial cells lining the breast ducts, and fibrous connective tissue. The clinical manifestations of breast hyperplasia are breast pain, local thickening of the breast tissue, or multiple nodules of different sizes $(1,2)$. The occurrence of breast hyperplasia can be associated with an increased risk for breast cancer. The incidence of breast cancer in patients with severe breast hyperplasia, atypical breast hyperplasia, and cystic breast hyperplasia, is significantly higher (3). However, the etiology of breast hyperplasia is not fully understood. The breast is one of the most complex endocrine target organs in the human body and represents the principal target for many hormones. The expression levels of the estrogen receptor (ER) and the progesterone receptor (PR) in breast tissue have been associated with the regulation of self-sensitivity in breast tissue (4). There is a general consensus of opinion among researchers that the occurrence of breast hyperplasia is closely related to the disruption of hormones and hormone receptors across the body $(5,6)$. Currently, the principle treatment for this disease is drug or surgical treatment. However, because these lesions generally adopt a diffuse distribution, it is usually impossible to remove all of the hyperplastic lesions. It is therefore impossible to cure this disease completely by surgery alone. It is vital that we develop appropriate drugs for the treatment of breast hyperplasia.

Melatonin (N-acetyl-5-methoxytryptamine) is an indoleamine, which is predominantly synthesized by the mammalian pineal gland. The synthesis and secretion of melatonin is controlled by light and dark conditions (7). Previous research has shown that melatonin can regulate the reproductive activities of several photoperiodic animals $(8,9)$. Early work indicated that the main function of melatonin was to regulate sleep $(10,11)$. However, subsequent studies have reported that melatonin has a multitude of effects against tumors (12) and in the regulation of immunity (13). With regards to the treatment of breast cancer, melatonin has been shown to reduce the growth rate of breast tumor cells and inhibit the invasion and metastasis of tumor cells. Indeed, such work indicated that melatonin could be a highly appropriate drug candidate for the treatment of breast tumors (14). 
Phosphatase and tensin homolog (PTEN) is an effective tumor-suppressor gene located on chromosome 10q23.31 (15); this is the only tumor-suppressor gene that has been identified to exhibit phosphatase activity. AKT (also referred to as protein kinase $\mathrm{B}$ ) is a serine-threonine kinase and is considered to act as a proto-oncogene (16). The abnormal expression of these kinases has been previously linked to tumorigenesis $(15,17)$. Previous studies have reported that breast cancer is associated with the abnormal activation of the PTEN/AKT pathway (14). In the present study, we investigated the molecular mechanisms underlying the effects of melatonin on breast hyperplasia. Our research identified the abnormal activation of PTEN/AKT in the hyperplastic breast tissue and that the degree of breast hyperplasia was significantly reduced following treatment with melatonin.

\section{Materials and methods}

Animals and the administration of treatments. Seventy-six virgin female Wistar rats were purchased from Cavens Lab Animal Co., Ltd. (Changzhou, China), weighing 180-220 g, were fed adaptively for one week and then randomly divided into two groups: A control group $(n=13)$ and a model group $(n=63)$. All animals were maintained under 12-h light and 12-h dark cycles at $22-24^{\circ} \mathrm{C}$ with free access to food and water. All rats in the model group, but not the control group, were treated with estrogen and progesterone to establish the rat model of breast hyperplasia. In brief, we injected $0.5 \mathrm{mg}$ of estradiol benzoate into the muscles of the hind legs alternately for 25 days. Then, we injected $4 \mathrm{mg}$ of progesterone for 5 consecutive days. Rats in the control group were injected with $0.1 \mathrm{ml}$ of saline into the muscles of the hind legs for 30 days. After fasting for $12 \mathrm{~h}$ on the 30 th day, we selected three rats from the control group and three rats from the model group. Using these animals, we removed the second pair of the right mammary glands to prepare pathological sections for analyses. We then used sections stained with hematoxylin eosin (H\&E) staining to verify the successful creation of the rat model of breast hyperplasia. During such analysis, we focused on the acini, ductal epithelium, and the mammary lobules. We observed obvious acinar and ductal epithelial hyperplasia, an increase in the diameter and number of mammary acini, an increase in the average diameter of the mammary lobules, and an increase in the number of mammary lobules. These results proved that the model had been successfully established. Rats in which the model had been successfully established were then randomly divided into a model group $(n=10)$, a negative control group $(n=10)$, a positive control group $(n=10)$, a melatonin group $(n=10)$, a PTEN-inhibitor group $(n=10)$, and an melatonin+PTEN-inhibitor group $(n=10)$. Saline was used as a solvent.

We administered the PTEN inhibitor bpV (HOpic, EMD Biosciences) at a dose of $500 \mu \mathrm{g} / \mathrm{kg}$ by local injection every 10 days. The negative control group was administered with normal saline, while rats in the positive control group were given tamoxifen. Saline was used as a control. The clinically equivalent dose was calculated as a dose reference (a factor of 6.25 of the adult unit body weight). The diameter and height of the second pair of nipples were measured using a precision Vernier caliper every 10 days. The overall duration of the experiments was 60 days. Prior to the experiment, the rats were fasted for $12 \mathrm{~h}$ and then anesthetized by intraperitoneal injection of a mixture of ketamine $(100 \mathrm{mg} / \mathrm{kg})$ and xylazine (5 mg/kg). During injection, we closely monitored the corneal reflex, muscle relaxation, and pain response. Following the induction of anesthesia, we applied hair removal cream to remove the fur around the second pair of mammary glands and aseptically removed the second pair of right mammary gland tissues. Some of these tissues were immediately stored in a freezer at $-80^{\circ} \mathrm{C}$ to await western blotting experiments. The rest of the tissues were fixed with $4 \%$ paraformaldehyde for 3 days, embedded in paraffin, and sectioned for H\&E staining. These sections were subsequently used to investigate histopathological changes in response to the different treatments. At the end of the experiment and under continuous anesthesia, the animals were euthanized by overdose of pentobarbital $(125 \mathrm{mg} / \mathrm{kg})$. All of the experiments were carried out in accordance with the Chinese regulations on the use and breeding of experimental animals and were approved by the Animal Experiment Center. All animal experiments complied with the ARRIVE guidelines and were carried out in accordance with the U.K. Animals (Scientific Procedures) Act, 1986 and associated guidelines.

Immunohistochemistry assay. First, we placed the paraffinembedded tissue sections into a $60^{\circ} \mathrm{C}$ incubator for $20 \mathrm{~min}$. These were then dewaxed twice in xylene for $10 \mathrm{~min}$. Next, the sections were hydrated with a graded series of ethanol concentrations (from high to low). The dewaxed and hydrated sections were then treated with citrate buffer (sodium citrate antigen retrieval solution; $10 \mathrm{mM}$ citric acid, $\mathrm{pH}$ 6.0) for $10 \mathrm{~min}$ and then washed three times in phosphate-buffered solution (PBS). The sections were then immersed in $3 \% \mathrm{H}_{2} \mathrm{O}_{2}$ at $37^{\circ} \mathrm{C}$ for $10 \mathrm{~min}$ and washed three times in PBS. The sections were incubated with $5 \%$ goat serum at $37^{\circ} \mathrm{C}$ for $15 \mathrm{~min}$ before being incubated overnight with a primary antibody at $4^{\circ} \mathrm{C}$. Two monoclonal antibodies were used: Rabbit anti-PCNA [dilution 1:500; cat. \#13110, Cell Signaling Technology, Inc. (CST)] and rabbit anti-cleaved-caspase-3 (dilution 1:1,000; cat. no. 9664, CST). The following morning, the sections were rinsed three times and then incubated with a goat anti-rabbit IgG second antibody (dilution 1:1,000; cat. no. ab7090, Abcam) at $37^{\circ} \mathrm{C}$ for $15 \mathrm{~min}$. The sections were then washed three times in PBS, incubated in Strept Avidin Biotin Complex for $15 \mathrm{~min}$ at $37^{\circ} \mathrm{C}$, and then stained with 3,3-diaminobenzidine tetrahydrochloride $(\mathrm{DAB})$ at $37^{\circ} \mathrm{C}$ for $5 \mathrm{~min}$. After staining with $\mathrm{DAB}$, the sections were re-stained with $\mathrm{H} \& \mathrm{E}$ and mounted with Permount (Thermo Fisher Scientific, Inc.). Finally, the sections were observed using an Olympus 1x70 light microscope (at magnifications of x200 and x400).

TUNEL assay. Paraffin-embedded tissue sections were placed in a $60^{\circ} \mathrm{C}$ incubator for $20 \mathrm{~min}$ and then dewaxed twice in xylene for $10 \mathrm{~min}$. We then hydrated the sections with ethanol with a gradient series of ethanol concentrations (from high to low). The dewaxed and hydrated sections were then incubated with $20 \mu \mathrm{g} / \mathrm{ml}$ of Protease $\mathrm{K}$ for $20 \mathrm{~min}$. TUNEL assay kits were purchased from Abcam and were used in accordance with the manufacturer's instructions. In brief, the TUNEL reaction was carried out at $37^{\circ} \mathrm{C}$ for $1 \mathrm{~h}$. After the reaction, the sections were washed three times with PBS, incubated with anti-fluorescein antibody-peroxidase (POD) for $30 \mathrm{~min}$, 

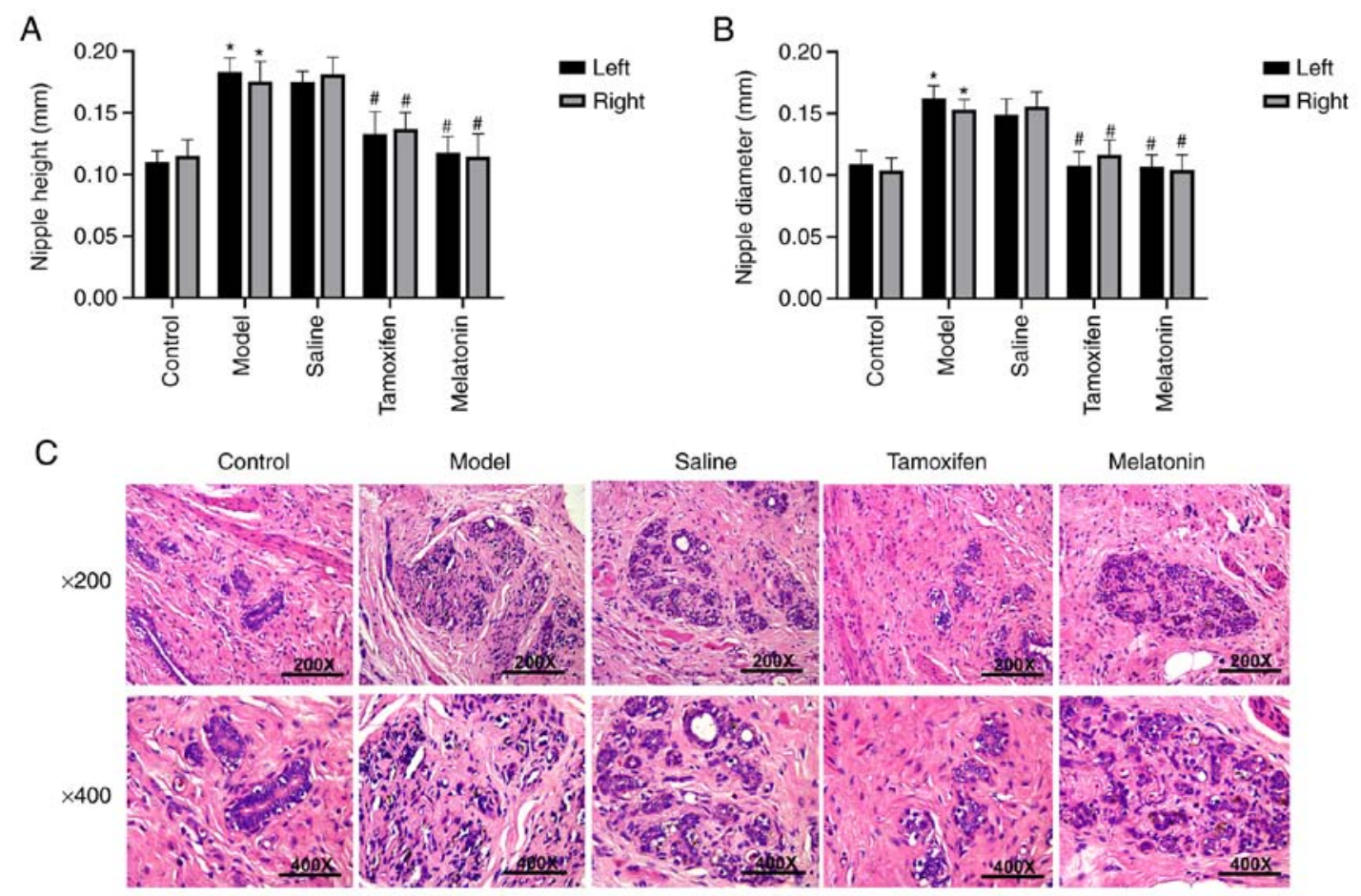

Figure 1. Height and diameter of the left and right nipples and the pathological features of rat breast tissue in each group. (A) Nipple length and (B) nipple diameter. (C) Hematoxylin and eosin staining (magnification, $\mathrm{x} 400$ and $\mathrm{x} 200$ ). Results are shown as means $\pm \mathrm{SEM}$ of three independent experiments. ${ }^{*} \mathrm{P}<0.05$ vs. control; ${ }^{\#} \mathrm{P}<0.05$ vs. saline group.

stained with DAB for 10 min, washed three times with PBS, and then re-stained with $H \& E$. Finally, sections were mounted with Permount. Sections were observed using an Olympus 1x70 light microscope (at magnifications of x200 and x400). Cells showing brown-stained nuclei were recorded as being positive. According to the distribution of apoptotic cells, we photographed 7 positive visual fields from each treatment group under a x400 objective. We then counted 200 cells in each visual field using Image-pro Plus 6.0 (Image-pro Plus, Media Cybernetics, Inc., USA). Then, we calculated the mean proportion of apoptotic cells (in \%) as the apoptotic index (AI) using Equation 1.

Equation 1: $\mathrm{AI}=$ the number of apoptotic cells/total number cells

Western blotting assays. Fresh breast tissues were crushed by grinding in liquid nitrogen. We then extracted whole cell proteins in RIPA buffer (CST) and determined protein concentrations using a BCA protein concentration detection kit (Thermo Fisher Scientific, Inc.). Protein lysate $(20 \mu \mathrm{g})$ was mixed with $4 \mathrm{X}$ SDS-PAGE loading buffer and boiled at $99^{\circ} \mathrm{C}$ for $5 \mathrm{~min}$. The proteins were then separated by $12 \%$ SDS-PAGE electrophoresis alongside a protein marker. Separated proteins were then transferred, along with the protein marker, onto a PVDF membrane. After transfer, the PVDF membrane was incubated with $5 \%$ skimmed milk at $37^{\circ} \mathrm{C}$ for $1 \mathrm{~h}$. The PDVF membrane was then incubated with several monoclonal antibodies at $4^{\circ} \mathrm{C}$ overnight: Rabbit anti-PTEN (dilution 1:1,000; cat. no. ab267787, Abcam), rabbit anti-p-AKT/AKT (dilution $1: 500$, cat. \#4060, CST), and rabbit anti-GAPDH (dilution 1:2,000; cat. no. ab8245, Abcam). After incubation with the primary antibody, the membrane was rinsed three times in
Tris-buffered saline Tween (TBST) for $10 \mathrm{~min}$. The rinsed membrane was then incubated with a secondary antibody, goat anti-rabbit IgG (dilution 1:2,000; cat. no. ab7090, Abcam), at $37^{\circ} \mathrm{C}$ for $2 \mathrm{~h}$. After incubation, the membrane was rinsed three times with TBST for $10 \mathrm{~min}$. After rinsing, positive antibody binding was revealed by an enhanced chemiluminescence (ECL) immunoblotting photoluminescence kit (Thermo Fisher Scientific, Inc.). The levels of each protein were then analyzed by Quantity One software version 4.4.0 (Bio-Rad Laboratories) and normalized to controls.

Statistical analysis. SPSS version 19.0 statistical software (SPSS Inc.) was used to analyze all experimental data. Experimental results are expressed as the mean \pm standard deviation (SD). Different groups were compared by one-way analysis of variance (ANOVA). We also carried out tests to determine the homogeneity of variance. If variances were uniform, then we carried out Fisher's least significant difference (LSD) analysis. However, if the variance was not uniform, then we used the Games-Howell test. Differences were considered to be statistically significant if $\mathrm{P}<0.05$.

\section{Results}

Changes in nipple diameter, height, and case characteristics. We found that nipple height and diameter were directly proportional to the severity of breast hyperplasia, and therefore, represent an intuitive index with which to reflect the degree of hyperplasia in mammary glands. As shown in Fig. 1A and B, both nipple diameter and nipple height in the model group were significantly wider and higher, respectively, than those in the control group $(\mathrm{P}<0.05)$. Compared to the model group, 


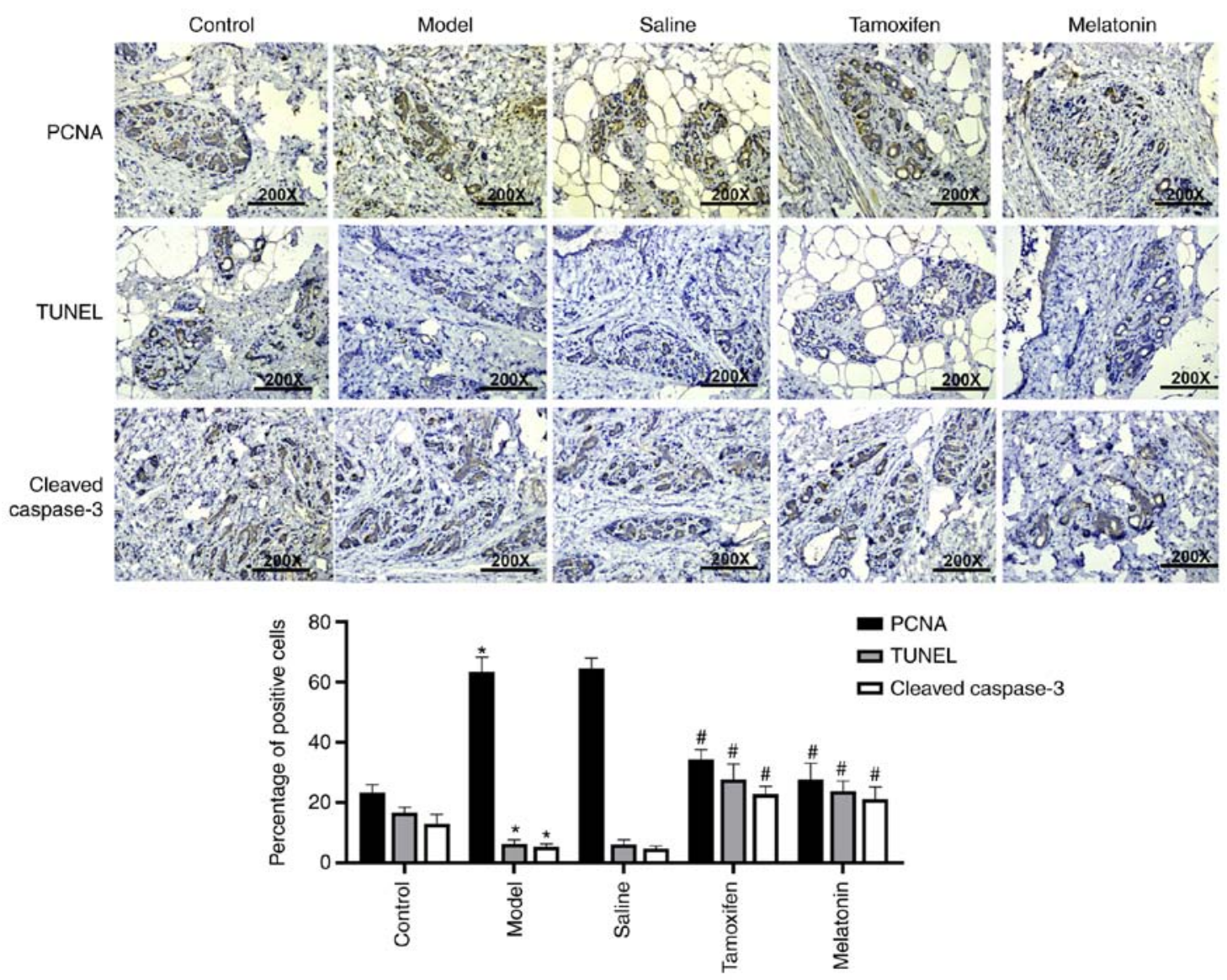

Figure 2. Melatonin inhibits cell proliferation in rats with breast hyperplasia. Immunohistochemistry was used to investigate the relative expression of genes associated with proliferation and apoptosis (magnification, $\mathrm{x} 200$ ). Results are shown as means \pm SEM of three independent experiments. ${ }^{*} \mathrm{P}<0.05 \mathrm{vs}$. control; ${ }^{\#} \mathrm{P}<0.05$ vs. saline group. PCNA, proliferating cell nuclear antigen.

all of the drug treatments led to a significant reduction in both nipple diameter and height in all groups, except for the negative control (saline) group $(\mathrm{P}<0.05)$. The therapeutic effect in the melatonin group was similar to that observed in the tamoxifen group.

Next, we investigated histological changes in each group by microscopy (Fig. 1C). We found that in the control group, the breast tissue was in a quiescent state, the epithelial cells of the mammary duct were arranged regularly, the ductal lumen and the acinar lumen were not dilated. In addition, there were only small numbers of lobular acini, and there was no interstitial hyperplasia. In the model group, there was significant hyperplasia of the breast acini and ductal epithelium, and the diameter and number of breast acini and breast lobules had increased significantly. In addition, we were able to visualize exfoliated epithelial cells and secretions in the breast acini and duct. In the melatonin and tamoxifen treatment groups, the degree of breast tissue hyperplasia was significantly alleviated, the arrangement of the epithelium cells in the mammary duct was slightly irregular, the acinar cavity and the ductal lumen were slightly dilated, a small number of acini were slightly hyperplastic, and the breast acini and ductal endocrine secretions were reduced. Our results demonstrated that melatonin can improve the pathological changes observed in breast tissue.

Melatonin inhibits cell proliferation in rats with breast hyperplasia. In order to determine the effect of melatonin on breast cell proliferation, we determined the expression of proliferating cell nuclear antigen (PCNA) and apoptotic protein cleaved-caspase-3 by immunohistochemistry. Analysis showed that PCNA was weakly positive in the ductal and acinar epithelial cells in the control group (shown as yellow or brown granular staining). Analysis also showed that there was a significantly lower number of cells that stained positive for cleaved-caspase- 3 in the model group than that noted in the control group, and also that this positive staining was distributed wider and was more intense. Compared with the other treatment groups, we found that the number of PCNA-positive cells was significantly lower in the melatonin and tamoxifen groups, and that the number of cells that showed positive staining for cleaved-caspase-3 was significantly higher than that in the model group (Fig. 2, P<0.05). Following TUNEL staining, we re-stained sections with hematoxylin. Cells showing brown nuclei were considered to be apoptotic. Analysis showed that there were almost no apoptotic cells in the control group (Fig. 2); however, the numbers of apoptotic cells in the melatonin group and the tamoxifen group were significantly higher.

\section{Melatonin regulates the PTEN/AKT pathway in rats with breast} hyperplasia. In order to investigate whether melatonin regulates breast hyperplasia via the PTEN/AKT pathway, western blotting was performed to determine the expression of PTEN, AKT, and phosphorylated (p-)AKT proteins in each group. As 

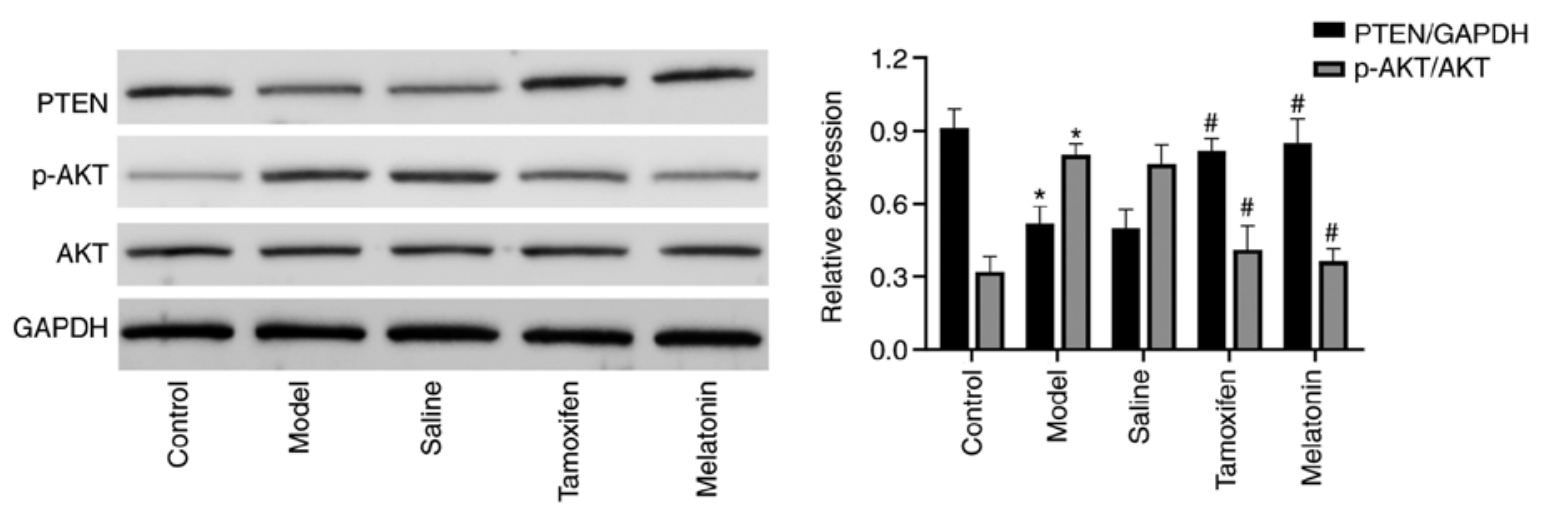

Figure 3. Expression of PTEN/AKT pathway proteins in hyperplastic breast tissue and normal breast tissue. Western blotting was used to detect the expression of PTEN/AKT protein in breast tissue. Results are shown as means \pm SEM of three independent experiments. ${ }^{*} \mathrm{P}<0.05$ vs. control; ${ }^{\#} \mathrm{P}<0.05$ vs. saline group. PTEN, phosphatase and tensin homolog; AKT, protein kinase B; p-, phosphorylated.

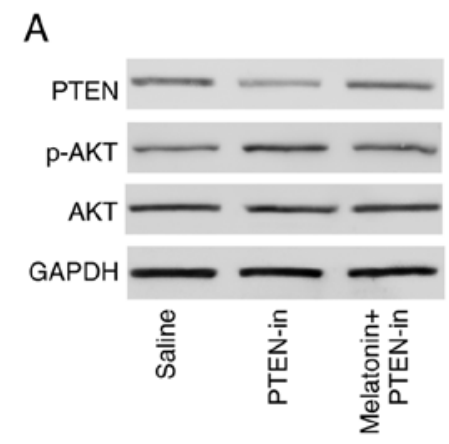

C

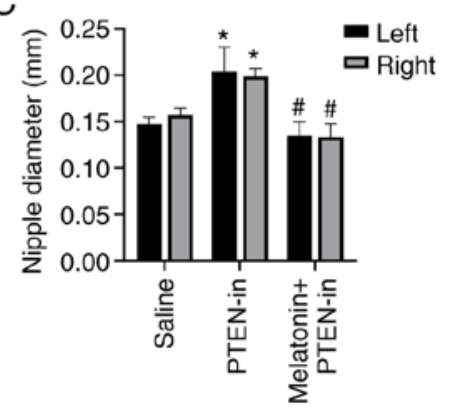

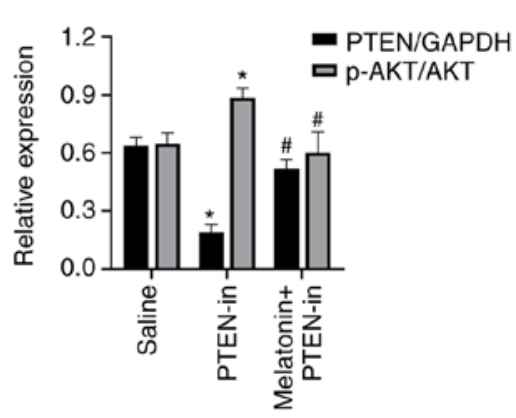
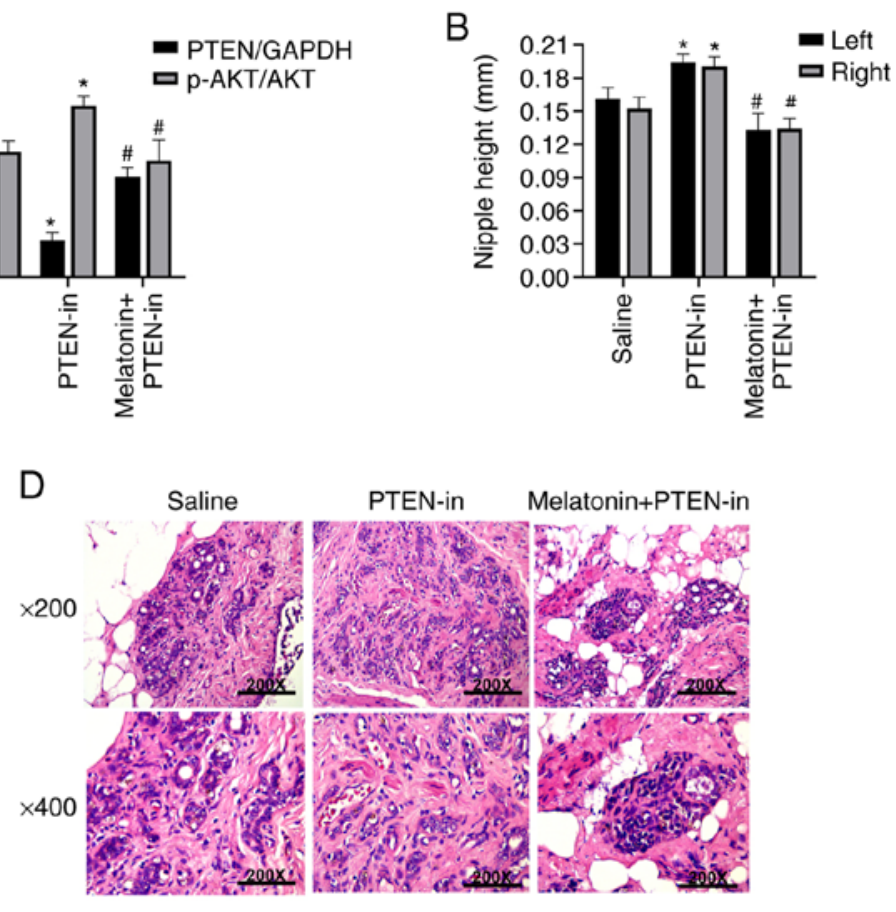

Figure 4. Melatonin weakens the effects of a PTEN inhibitor (PTEN-in) on the height and diameter of the left and right nipples, and the pathological features of rats with breast hyperplasia. (A) Western blotting was used to detect the expression of PTEN/AKT protein in breast tissue. (B) Nipple length. (C) Nipple diameter. (D) Hematoxylin and eosin staining (magnification, $\mathrm{x} 400$ and $\mathrm{x} 200$ ). Results are shown as means $\pm \mathrm{SEM}$ of three independent experiments. ${ }^{*} \mathrm{P}<0.05$, ${ }^{\#} \mathrm{P}<0.05$ vs. PTEN-in treated group. PTEN, phosphatase and tensin homolog; AKT, protein kinase B; p-, phosphorylated.

shown in Fig. 3, the expression of PTEN in the control breast tissue was significantly higher than in the model group, and the expression of p-AKT/AKT in normal breast tissue was significantly lower than that in the model group $(\mathrm{P}<0.05)$. Changes were also detected in the expression of PTEN and p-AKT/AKT in each treatment group. Results showed that the expression of PTEN was significantly increased in the tamoxifen and melatonin groups $(\mathrm{P}<0.05)$ while the expression of $\mathrm{p}-\mathrm{AKT} / \mathrm{AKT}$ was significantly decreased $(\mathrm{P}<0.05)$. These results suggested that the effect of melatonin on hyperplasia in the mammary glands of rats is achieved via the PTEN/AKT pathway.

Melatonin weakens the effects of a PTEN inhibitor in rats with breast hyperplasia. In order to further confirm that melatonin regulates cell proliferation in hyperplastic breast tissue via the PTEN/AKT signaling pathway, our rat model was administered a special PTEN inhibitor bpV (HOpic). Expression of PTEN was significantly inhibited and that the expression of p-AKT/AKT had significantly increased in the PTEN-in group compared with the control group $(\mathrm{P}<0.05)$. In addition, expression of PTEN in the melatonin+PTEN-in group was significantly higher than that in the PTEN-in group $(\mathrm{P}<0.05)$, while expression of $\mathrm{p}-\mathrm{AKT} / \mathrm{AKT}$ was significantly inhibited $(\mathrm{P}<0.05)$. These data suggested that melatonin can weaken the activity of the PTEN/AKT signaling pathway (Fig. 4A). We also measured changes in nipple diameter and height across the different groups. Results showed that nipple height and nipple diameter increased significantly in the PTEN-in 

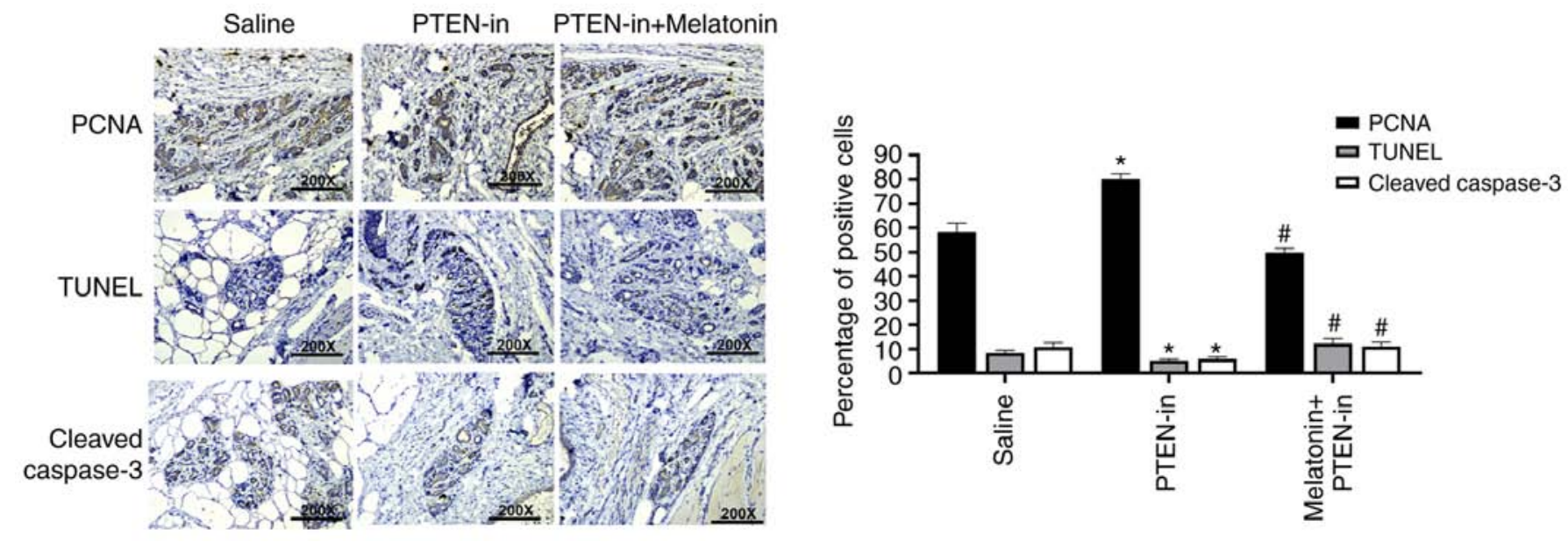

Figure 5. Melatonin weakens the effects of PTEN inhibitor (PTEN-in) on cell proliferation in rats with breast hyperplasia. Immunohistochemistry was used to detect the expression of genes associated with proliferation and apoptosis (magnification, x200). Results are shown as means \pm SEM of three independent experiments. ${ }^{*} \mathrm{P}<0.05,{ }^{\#} \mathrm{P}<0.05$ vs. PTEN-in treated group. PTEN, phosphatase and tensin homolog; PCNA, proliferating cell nuclear antigen.

group. Furthermore, in the melatonin+PTEN-in group, we found that nipple diameter and height was significantly lower than these parameters in the PTEN-in group $(\mathrm{P}<0.05)$, thus, suggesting that breast hyperplasia was significantly reduced (Fig. 4B and C). We used H\&E staining to investigate the effect of melatonin on the degree of breast hyperplasia under the intervention of a PTEN-inhibitor. In the melatonin+PTEN-in group, we observed that the breast hyperplasia had been significantly alleviated and was not affected by the PTEN inhibitor (Fig. 4D). These results suggested that melatonin can weaken the aggravation of breast hyperplasia caused by the administration of PTEN inhibitor.

The expression of PCNA and cleaved-caspase-3 were detected by immunohistochemistry in the PTEN-in group and the melatonin+PTEN-in group. Data showed that the expression of PCNA was significantly higher in the PTEN-in group while the expression of cleaved-caspase-3 was significantly lower $(\mathrm{P}<0.05$; Fig. 5$)$. Compared with the PTEN-in group, the expression of PCNA was significantly lower in the melatonin+PTEN-in group, while the expression of cleaved-caspase- 3 was significantly higher $(\mathrm{P}<0.05)$. TUNEL staining results were consistent with the expression of cleaved-caspase-3. This suggested that melatonin can reduce the proliferation of breast tissue cells caused following administration of the PTEN inhibitor.

\section{Discussion}

Breast hyperplasia refers to hyperplasia of the breast epithelium and fibrous tissue caused by endocrine imbalance and the structural degeneration of breast ducts and breast lobules $(18,19)$. Breast hyperplasia is a common benign disease of the breast and occurs during the normal development and degeneration of female breasts. Globally, breast hyperplasia is ranked as the leading cause of female breast disease. If the disease persists for a long period of time, it can develop into pre-cancerous lesions or even the development of breast cancer, thus, representing a serious risk for public health and the safety of women (20). Over recent years, there has been a gradual increase in the incidence of breast hyperplasia; furthermore, the age at onset has become younger. It is commonly believed that the increases incidence of this condition is related to changes in social rhythm and life pressure. Moreover, this condition causes serious adverse effects on the physical and mental health of women of childbearing age (21). A recent study showed that the incidence of breast hyperplasia is increasing by 2.7 -fold each year, while the probability of breast cancer in patients with breast hyperplasia is 1.4- to 1.5 -fold higher than that of healthy women (22). At present, tamoxifen, toremifene, and other drugs, are predominantly used for the treatment of breast hyperplasia $(23,24)$. However, patient compliance for such treatment is poor. This is due to the requirements for long-term treatment and the associated risk of a series of side effects (25). Therefore, there is a critical need to identify new drugs that are effective for the treatment of breast hyperplasia, but with fewer side effects and better outcomes.

In the present study, we found that melatonin performed well in alleviating breast hyperplasia and achieved the same therapeutic effect as tamoxifen. We established a rat model of breast hyperplasia induced by estradiol benzoate and progesterone and then explored the molecular mechanisms underlying the effects of melatonin in the treatment of breast hyperplasia. By measuring changes in nipple height and diameter, and by investigating the pathological changes of breast tissue following H\&E staining; we found that the degree of breast hyperplasia was significantly reduced after melatonin treatment. Next, we determined the expression of proliferating cell nuclear antigen (PCNA) and cleaved-caspase-3 protein, and evaluated proliferation and apoptosis in breast tissue. PCNA is an essential requirement for DNA replication. The expression and synthesis of PCNA is closely related to cell proliferation, and is therefore, an important index with which to evaluate the state of cell proliferation (26). Our results showed that the expression of PCNA in the model group was significantly higher $(\mathrm{P}<0.05)$. These data showed that the breast tissue had high rates of proliferation during the onset of breast hyperplasia. After treatment, we found that the expression of PCNA decreased, thus, indicating that melatonin can significantly reduce cell proliferation in breast hyperplasia. Caspase- 3 is the 
most important executor of apoptosis in the caspase family, and represents the final common substrate of both endogenous and exogenous apoptosis pathways. Activated caspase- 3 can cleave substrate to induce apoptosis, and therefore, represents an important parameter with which to reflect apoptosis. By measuring the expression levels or the activity of activated caspase-3, we can indirectly reflect the level of apoptosis (27). By detecting the expression levels of cleaved-caspase-3, we found that the expression levels of cleaved-caspase-3 were lower in the disease model group, thus suggesting that apoptosis had been inhibited. We also found that the expression of cleaved-caspase-3 had increased significantly in the treatment group, thus suggesting that melatonin can promote apoptosis in hyperplastic breast tissue cells. In the present study, we also used TUNEL staining and the expression of cleaved-caspase-3 to provide evidence for apoptosis; these two techniques yielded similar results. Consequently, our data suggested that the effects of melatonin in the treatment of breast hyperplasia are similar to, or even better than, tamoxifen.

Previous studies have found that melatonin has a significant effect on breast cancer and is a good candidate drug for the treatment of breast cancer (14). Furthermore, experimental studies have found that melatonin inhibits cell proliferation and induces apoptosis by inhibiting the COX-2/PGE2, p300/NF- $\mathrm{B}$, and PI3K/AKT signaling pathways, and by activating the APAF-1/caspase-dependent apoptotic pathways in breast cancer cells (28). We found that the phosphatase and tensin homolog (PTEN)/protein kinase B (AKT) signaling pathway was abnormally activated in breast hyperplasia and observed low levels of PTEN protein in the disease model group; however, the levels of PTEN protein increased significantly after melatonin treatment. PTEN is a widely studied tumor-suppressor gene. Many human cancers are associated with somatic deletion or mutation of the PTEN gene, including endometrial carcinoma (29), skin (30), breast (31) and prostate cancer (32). The inactivation of PTEN gene protein products in breast cancer is associated with tumor cell invasion and metastasis (33). PTEN is a phosphatase (34), which is the main negative regulator of class I phosphatidylinositol-3-kinases (PI3Ks) (35). PTEN can inhibit the conversion of phosphatidylinositol-4-diphosphate (PIP2) to phosphatidylinositol-3-triphosphate (PIP3) (36). The reduction or total loss of PTEN activity is known to contribute to the activation of the PI3K pathway (37). An increase in the levels of PIP3 in cancer cells can inhibit apoptosis and affect the growth and proliferation of tumor cells (38). In our study, the expression levels of PTEN protein in the model of breast hyperplasia were low. In contrast, the expression levels of PTEN protein were high in normal breast tissue. There was a significant difference between the two groups $(\mathrm{P}<0.05)$, thus, indicating that breast hyperplasia is associated with low levels of PTEN protein.

AKT is a key gene in the PTEN/AKT pathway and acts as a proto-ncogene that encodes a $58-\mathrm{kDa}$ protein that is overexpressed in numerous human malignancies (39). The AKT protein contains 480 amino acids, with catalytic sites at both the N-terminal and C-terminal that are phosphorylated by PDK and PI3K, respectively (40). Once activated, AKT produces $\mathrm{p}$-Akt, which can promote tumor progression (41). PTEN exerts its role mainly via the PI3K/AKT signaling pathway. When PTEN is expressed at high levels, PIP2 is phosphorylated by PI3K; levels of PIP2 increase in the nucleus and therefore inhibit the PI3K/AKT pathway. When PTEN is expressed at low levels, there is a large-scale accumulation of PIP3. This also leads to a significant reduction in the level of apoptosis. The reason for this is because AKT is always in a state of activation, thus inducing a variety of tumors (41-43). Western blotting data further showed that the expression levels of PTEN consistently opposed those of p-AKT/AKT. The expression of p-AKT/AKT was upregulated in the disease model group, but significantly inhibited in the treatment groups $(\mathrm{P}<0.05)$. In the present study, we applied a special PTEN inhibitor bpV (HOpic) to inhibit PTEN activity in our rat model. Data showed that the extent of breast hyperplasia was significantly higher in the PTEN-in group, as compared with the disease model group. Furthermore, the height and diameter of the nipple were significantly higher $(\mathrm{P}<0.05)$, the proliferation of breast tissue cells was significantly increased, and the extent of apoptosis was inhibited. These data indicated that PTEN had a regulatory effect on the proliferation of breast tissue cells. In the melatonin and PTEN-in groups, it was clear that melatonin significantly attenuated the breast hyperplasia induced by a PTEN inhibitor, thus, suggesting that melatonin can alleviate breast hyperplasia via PTEN.

In regards to the limitations, in our study, we did not conduct a detailed study of the therapeutic window and side effects during melatonin treatment of breast hyperplasia. Thus, further in-depth studies will be conducted to provide more research information in order to timely promote the use of melatonin in clinical treatment.

To conclude, our results indicate that melatonin is an effective means of treating breast hyperplasia, and that the PTEN/AKT pathway shows abnormal activation in breast hyperplasia. Our data also showed that the expression levels of proteins associated with the PTEN/AKT pathway were related to the degree of breast hyperplasia. Our data indicate that melatonin can play a therapeutic role by regulating the PTEN/PI3K/AKT axis. Our data indicate that melatonin may represent an ideal drug for the treatment of breast hyperplasia.

\section{Acknowledgements}

Not applicable.

\section{Funding}

This research did not receive any specific grant from funding agencies in the public, commercial, or not-for-profit sectors.

\section{Availability of data and materials}

The data used to support the findings of this study are available from the corresponding author upon request.

\section{Authors' contributions}

XZ WA responsible for project development and manuscript writing. YN conducted the data collection. YH was responsible for data collection and manuscript writing. All authors read and 
approved the manuscript and agree to be accountable for all aspects of the research in ensuring that the accuracy or integrity of any part of the work are appropriately investigated and resolved.

\section{Ethics approval and consent to participate}

All protocols followed the requirements of the Animal Experiment Center. All of the experiments were carried out in accordance with the Chinese regulations on the use and breeding of experimental animals and were approved by the Animal Experiment Center. All animal experiments complied with the ARRIVE guidelines and were carried out in accordance with the U.K. Animals (Scientific Procedures) Act, 1986 and associated guidelines.

\section{Patient consent for publication}

Not applicable.

\section{Competing interests}

The authors declare that there are no competing interests.

\section{References}

1. Huang J, Tang H, Cao S, He Y, Feng Y, Wang K and Zheng Q: Molecular targets and associated potential pathways of danlu capsules in hyperplasia of mammary glands based on systems pharmacology. Evid Based Complement Alternat Med 2017: 1930598, 2017.

2. Meyer JS: Cell proliferation in normal human breast ducts, fibroadenomas, and other ductal hyperplasias measured by nuclear labeling with tritiated thymidine. Effects of menstrual phase age, and oral contraceptive hormones. Hum Pathol 8: 67-81, 1977.

3. Hartmann LC, Degnim AC, Santen RJ, Dupont WD and Ghosh K: Atypical hyperplasia of the breast-risk assessment and management options. N Engl J Med 372: 78-89, 2015.

4. Oh H, Eliassen AH, Wang M, Smith-Warner SA, Beck AH, Schnitt SJ, Collins LC, Connolly JL, Montaser-Kouhsari L, Polyak K and Tamimi RM: Expression of estrogen receptor, progesterone receptor, and Ki67 in normal breast tissue in relation to subsequent risk of breast cancer. NPJ Breast Cancer 2: 16032, 2016.

5. Lee S, Mohsin SK, Mao S, Hilsenbeck SG, Medina D and Allred DC: Hormones, receptors, and growth in hyperplastic enlarged lobular units: Early potential precursors of breast cancer. Breast Cancer Res 8: R6, 2006.

6. Wood CE, Hester JM, Appt SE, Geisinger KR and Cline JM: Estrogen effects on epithelial proliferation and benign proliferative lesions in the postmenopausal primate mammary gland. Lab Invest 88: 938-948, 2008.

7. Wurtman RJ, Axelrod J and Phillips LS: Melatonin synthesis in the pineal gland: Control by light. Science 142: 1071-1073, 1963.

8. Majidinia M, Reiter RJ, Shakouri SK and Yousefi B: The role of melatonin, a multitasking molecule, in retarding the processes of ageing. Ageing Res Rev 47: 198-213, 2018.

9. Mura MC, Luridiana S, Pulinas L, Bizzarri D, Cosso G and Carcangiu V: Melatonin treatment and male replacement every week on the reproductive performance in Sarda sheep breed. Theriogenology 135: 80-84, 2019.

10. Arendt J, Bojkowski C, Folkard S, Franey C, Marks V, Minors D, Waterhouse J, Wever RA, Wildgruber C and Wright J: Some effects of melatonin and the control of its secretion in humans. Ciba Found Symp 117: 266-283, 1985.

11. Zhdanova IV, Wurtman RJ, Regan MM, Taylor JA, Ping SJ and Leclair OU: Melatonin treatment for age-related insomnia. J Clin Endocrinol Metab 86: 4727-30, 2001.

12. Cutando A, López-Valverde A, Arias-Santiago S, DE Vicente J and DE Diego RG: Role of melatonin in cancer treatment Anticancer Res 32: 2747-2753, 2012.

13. Szczepanik M: Melatonin and its influence on immune system. J Physiol Pharmacol 58 (Suppl 6): S115-S124, 2007.
14. Amin N, Shafabakhsh R, Reiter RJ and Asemi Z: Melatonin is an appropriate candidate for breast cancer treatment: Based on known molecular mechanisms. J Cell Biochem 120: 12208-12215, 2019.

15. Jiang BH and Liu LZ: PI3K/PTEN signaling in angiogenesis and tumorigenesis. Adv Cancer Res 102: 19-65, 2009.

16. Franke TF, Yang SI, Chan TO, Datta K, Kazlauskas A, Morrison DK, Kaplan DR and Tsichlis PN: The protein kinase encoded by the Akt proto-oncogene is a target of the PDGF-activated phosphatidylinositol 3-kinase. Cell 81: 727-736, 1995.

17. Mccubrey J, Steelman LS, Abrams SL, Lee JT, Chang F, Bertrand FE, Navolanic PM, Terrian DM, Franklin RA, D'Assoro AB, et al: Roles of the RAF/MEK/ERK and PI3K/PTEN/AKT pathways in malignant transformation and drug resistance. Adv Enzyme Regul 46: 249-279, 2006.

18. Sainsbury R: Benign disorders and diseases of the Breast. Breast 1: 113-113, 1992.

19. Chen CQ and Dan Y: Research of changes of endocrine hormones in mammary cancer and hyperplasia of mammary glands. J Modern Oncol 6: 57-59, 2005 (In Chinese with English abstract).

20. Hartmann LC, Sellers TA, Frost MH, Lingle WL, Degnim AC, Ghosh K, Vierkant RA, Maloney SD, Pankratz VS, Hillman DW, et al: Benign breast disease and the risk of breast cancer. N Engl J Med 353: 229-237, 2005.

21. Knabben L and Mueller MD: Breast cancer and pregnancy. Horm Mol Biol Clin Investig: 32, 2017 doi: 10.1515/hmbci-2017-0026.

22. Wang L, Zhao D, Di L, Cheng D, Zhou X, Yang X and Liu Y: The anti-hyperplasia of mammary gland effect of Thladiantha dubia root ethanol extract in rats reduced by estrogen and progestogen. J Ethnopharmacol 134: 136-140, 2011.

23. Li HT, Liu HH, Yang YX, Wang T, Zhou XL, Yu Y, Li SN, Zheng Y, Zhang P, Wang RL, et al: Therapeutic effects of a traditional Chinese medicine formula plus tamoxifen vs. Tamoxifen for the treatment of mammary gland hyperplasia: A meta-analysis of randomized trials. Front Pharmacol 9: 45, 2018.

24. Goldstein SR, Suresh S, Ciaccia AV and Plouffe L Jr: Apharmacological review of selective oestrogen receptor modulators. Hum Reprod Update 6: 212-224, 2000.

25. Henry NL: Endocrine therapy toxicity: Management options. Am Soc Clin Oncol Educ Book: e25-e30, 2014 doi: 10.14694/EdBook_AM.2014.34.e25.

26. Muskhelishvili L, Latendresse JR, Kodell RL and Henderson EB: Evaluation of cell proliferation in rat tissues with BrdU, PCNA, Ki-67(MIB-5) immunohistochemistry and in situ hybridization for histone mRNA. J Histochem Cytochem 51: 1681-1688, 2003.

27. Duan WR, Garner DS, Williams SD, Funckes-Shippy CL, Spath IS and Blomme EA: Comparison of immunohistochemistry for activated caspase- 3 and cleaved cytokeratin 18 with the TUNEL method for quantification of apoptosis in histological sections of PC-3 subcutaneous xenografts. J Pathol 199: 221-228, 2003.

28. Wang J, Xiao X, Zhang Y, Shi D, Chen W, Fu L, Liu L, Xie F, Kang T, Huang W and Deng W: Simultaneous modulation of COX-2, p300, Akt, and Apaf-1 signaling by melatonin to inhibit proliferation and induce apoptosis in breast cancer cells. J Pineal Res 53: 77-90, 2012.

29. Oda K, Stokoe D, Taketani Y and McCormick F: High frequency of coexistent mutations of PIK3CA and PTEN genes in endometrial carcinoma. Cancer Res 65: 10669-10673, 2005.

30. Ming M and He YY: PTEN: New insights into its regulation and function in skin cancer. J Invest Dermatol 129: 2109-2112, 2009.

31. Janaki RM and Vaishnave S: BMI1 and PTEN are key determinants of breast cancer therapy: A plausible therapeutic target in breast cancer. Gene 678: 302-311, 2018.

32. Kwabi-Addo B, Giri D, Schmidt K, Podsypanina K, Parsons R, Greenberg N and Ittmann M: Haploinsufficiency of the Pten tumor suppressor gene promotes prostate cancer progression. Proc Natl Acad Sci USA 98: 11563-11568, 2001.

33. Giri D and Ittmann M: Inactivation of the PTEN tumor suppressor gene is associated with increased angiogenesis in clinically localized prostate carcinoma. Hum Pathol 30: 419-424, 1999.

34. Bonneau D and Longy M: Mutations of the human PTEN gene. Hum Mutat 16: 109-122, 2000.

35. Guillard S, Clarke PA and Workman P: Investigating the function of class I phosphatidylinositol 3-kinase isoforms in glioma cell lines by siRNA-mediated depletion. Cancer Res 66: 998-998, 2006.

36. Wei Y, Stec B, Redfield AG, Weerapana E and Roberts MF: Phospholipid-binding sites of phosphatase and tensin homolog (PTEN): Exploring the mechanism of phosphatidylinositol 4,5-bisphosphate activation. J Biol Chem 290: 1592-606, 2015. 
37. Goschzik T, Gessi M, Denkhaus D and Pietsch T: PTEN mutations and activation of the PI3K/Akt/mTOR signaling pathway in papillary tumors of the pineal region. J Neuropathol Exp Neurol 73: 747-751, 2014

38. Leslie NR, Kriplani N, Hermida MA, Alvarez-Garcia V and Wise HM: The PTEN protein: Cellular localization and post-translational regulation. Biochem Soc Trans 44: 273-278, 2016.

39. Datta SR, Brunet A and Greenberg ME: Cellular survival: A play in three Akts. Genes Dev 13: 2905-2927, 1999.

40. Dennis PA: The PI3K/Akt/mTOR signaling pathway. Ann Oncol: 19, 2011.

41. Lu XX, Cao LY, Chen X, Xiao J and Chen Q: PTEN inhibits cell proliferation, promotes cell apoptosis, and induces cell cycle arrest via downregulating the PI3K/AKT/hTERT pathway in lung adenocarcinoma A549 cells. Biomed Res Int 2016: 2476842, 2016.
42. He L, Fan C, Gillis A, Feng X, Sanatani M, Hotte S, Kapoor A and Tang D: Co-existence of high levels of the PTEN protein with enhanced Akt activation in renal cell carcinoma. Biochim Biophys Acta 1772: 1134-1142, 2007.

43. Carnero A, Blanco-Aparicio C, Renner O, Link W and Leal JF: The PTEN/PI3K/AKT signalling pathway in cancer, therapeutic implications. Curr Cancer Drug Targets 8: 187-198, 2008.

(i) (9) This work is licensed under a Creative Commons Attribution-NonCommercial-NoDerivatives 4.0 International (CC BY-NC-ND 4.0) License. 